This is an electronic reprint of the original article. This reprint may differ from the original in pagination and typographic detail.

Author(s): Ojala, Arto; Tyrväinen, Pasi

Title: $\quad$ Value Networks in Cloud Computing

Year: $\quad 2011$

Version:

Please cite the original version:

Ojala, A., \& Tyrväinen, P. (2011). Value Networks in Cloud Computing. Journal of Business Strategy, 32(6), 40-49. https://doi.org/10.1108/02756661111180122

All material supplied via JYX is protected by copyright and other intellectual property rights, and duplication or sale of all or part of any of the repository collections is not permitted, except that material may be duplicated by you for your research use or educational purposes in electronic or print form. You must obtain permission for any other use. Electronic or print copies may not be offered, whether for sale or otherwise to anyone who is not an authorised user. 


\section{Value networks in cloud computing}

\section{Contact information ${ }^{1}$}

Arto Ojala (corresponding author)

Department of Computer Science and Information Systems

P.O. Box 35

40014 University of Jyväskylä

Finland

Phone: +358504285275

Email: arto.k.ojala@jyu.fi

Pasi Tyrväinen

Department of Computer Science and Information Systems

P.O. Box 35

40014 University of Jyväskylä

Finland

Phone: +358 405408646

Email: pasi.tyrvainen@jyu.fi

\section{Author biographies}

Dr. Arto Ojala is a Senior Researcher at the Cloud Software Program in the Department of Computer Science and Information Systems at the University of Jyväskylä. He received his $\mathrm{PhD}$ at the University of Jyväskylä in 2008. His research interests include software business, international entrepreneurship, and the internationalization of software firms. He is also an Adjunct Professor in International Entrepreneurship at the Jyväskylä University School of Business and Economics. His articles have appeared in publications such as Journal of International Marketing, IEEE Software, International Business Review, Journal of International Entrepreneurship, and European Management Journal. He is also on the editorial board of the Journal of Small Business Management.

\footnotetext{
${ }^{1}$ Final draft, Published in Journal of Business Strategy, Vol. 32 No. 6, pp. 40-49, 2011.
} 
Dr. Pasi Tyrväinen is Professor of Information Systems at the University of Jyväskylä. He received his doctoral degree at Helsinki University of Technology in 1994. His previous affiliations include R\&D management positions at Honeywell Industrial Control and Nokia Research Center. His research interests include enterprise content management and software business, related to which in 2010 he initiated the ICSOB conference series on software business research. His articles have appeared in publications such as IEEE software, Journal of International Marketing, European Journal of Information Systems, and Journal of International Entrepreneurship. 


\title{
Value networks in cloud computing
}

\begin{abstract}
Purpose - This paper examines value networks in cloud computing. It demonstrates the kinds of value offered by such networks to firms within a given network, and considers how and why the network may change over time.
\end{abstract}

Design/methodology/approach - The paper reports on a longitudinal case study, including a total of seven semi-structured open-ended interviews, conducted with five informants from the case firm.

Findings - It was found that cooperation in value networks provides not merely financial benefits, but also knowledge, plus intangible benefits. Value networks should be evaluated as a whole, since there may be indirect connections - i.e. the value comes not directly from customers, but through the partners in the network. The study also shows the dynamic nature of value networks, as illustrated by changes in a network that were based on transformations in the market environment, and on product development.

Originality/value - This paper contributes to an understanding of value networks and their dynamics, and of cloud computing. In addition, the paper looks at a value network in cloud computing from the service provider's point of view - an aspect that has been neglected in previous studies (Armbrust et al., 2010).

Keywords: Value networks, Cloud computing, SaaS, Cloud gaming 


\section{Introduction}

In business networks, firms share common interests, which motivate them to develop relationships with each other for their mutual benefit (Johanson and Mattsson, 1988; Johanson and Vahlne, 2003). The benefits thus offered form value networks. In e-commerce businesses, where the product is intangible, and where knowledge is one of the main resources of the firms (Allee, 2000), the term "value network" is a useful alternative to the term "value chain" (which is commonly used in industrial production). These value networks are dynamic: they may change when a firm deepen its existing relationships, establishes new ones, or ends problematic ones (Griffith and Harvey, 2004; Larson and Starr, 1993).

This case study examines the value network of a cloud service provider. In line with Armbrust et al. (2010), cloud computing is defined here as covering (i) software applications delivered through the Internet, and also (ii) the hardware and system software that is used within data centers to provide those services. In other words, in cloud computing, software is available for end-users through the Internet as a service (also called Software-as-a-Service and abbreviated to SaaS). This model frees users to use the software without worrying about installation, updates, version requirements, operating systems, memory capacity, or other technical issues. Examples of SaaS applications include Google docs, Facebook, online banking, and SalesForce.

Value networks in cloud computing are attracting increasing attention because of the dramatic growth in cloud computing. By the end of 2011, at least 35 percent of medium-sized enterprises in the US will be using cloud computing solutions, and 40 percent of small and medium-sized enterprises in the world will be using cloud computing-based applications (Telecom-IT, 2011). According to market estimates by Gartner and International Data Corporation (IDC), cloud services have already exceeded a market volume of 50 billion USD and are growing annually by $20-25 \%$. IDC has predicted that in the near future nearly $65 \%$ of new products from established software firms will be delivered as SaaS 
services, and nearly $85 \%$ of new software firms entering the market will be built around SaaS service composition and delivery (SIIA, 2011).

Recognizing the importance of value networks in marketing and selling intangible products (Allee, 2000, 2008; Baxter and Matear, 2004; Kothandaraman and Wilson, 2001; Westerlund and Svahn, 2008) and the strong growth in cloud computing, this study aimed to investigate value networks in cloud computing. More specifically, the study sought to demonstrate the kinds of value offered by the value network to firms within the network, and to look at how and why the network can change over time. The research questions were these:

(1) What are the values of a firm's product for the actors in a network?

(2) How does the value network change over time?

\section{Value networks}

Networks can be divided into business (industrial) networks and social (personal) networks, depending on the level of analysis. In business networks, a firm may have network ties with different types of actors, for example with customers, distributors, suppliers, competitors, non-profit organizations, and bodies in public administration. In the industrial network model, a firm is dependent on resources controlled by other firms, and the firm can compensate for its limited resources, either by developing its position in an existing network or by establishing new networks (Johanson and Mattsson, 1988). Considered in terms of the benefits

gained, these are value networks, offering mutual benefit to the actors within the network.

For a firm, it is important to recognize who the actors are (or will be) in the firm's value network. The firm needs to identify the value of the firm's offering, plus how this value can be delivered in such a way as to benefit all the actors in the network. By defining the value network, a firm can map all the actors that could benefit from its product offering, and in that way it can add value from its product to end-users. Doing this can also help a firm to avoid unnecessary partners, i.e. actors who will not add value to its product - bearing in mind that 
poorly-selected partners may cause harm to the firm (such as limiting access to important information or resources). The firm's value network may include suppliers, customers, and strategic partners - all of whom are capable of adding value to each other's products (Allee, 2008). Thus, in the value network, the ideal partner adds value to the firm's market offering, while at the same time minimizing the risk connected with partnering (Kothandaraman and Wilson, 2001).

According to Anderson et al. $(1993,5)$, value in business markets is "the perceived worth in monetary units of the set of economic, technical, service and social benefits received by a customer firm in exchange for the price paid for a product offering, taking into consideration the available alternative suppliers' offerings and prices." These researchers also emphasize that the value of a firm's product is the cornerstone of its marketing strategy. Hence, value drives a firm's decisions about product development, modification, pricing, and distribution (Anderson et al., 1993). Allee (2000) divides the "currencies" of the value network as follows: (i) Goods, Services, and Revenue, which refers to material exchanges in the network, (ii) Knowledge, which refers to the exchange of knowledge regarding the core product or service in the network, and (iii) Intangible benefits, related to exchanged values that go beyond actual services, and which are not accounted in the financial sense (although the benefits might have financial value later on).

Networks may change over time (Larson and Starr, 1993; Prashantham and Dhanaraj, 2010). These changes may be based on changing market conditions or on a firm's product development. This means that the value of the firm to other actors in the network may increase or decrease. For success in the market, a firm has to react to changing situations by establishing new networks, developing further its existing relationships, and ending problematic or unnecessary relationships. In other words, by actively following changes in the market, a firm develops and secures its position in the value network. 


\section{Value networks in cloud computing}

Cloud computing is currently transforming value networks related to information systems. The old model - in which a user organization purchased and maintained hardware, operating systems, and applications in private premises - is being replaced by usage of on-demand computing and storage infrastructure capacity, and by SaaS. SaaS applications transform multiple seller-buyer relationships into a single subscription to an SaaS service, obtained from a provider who orchestrates the underlying network. The network takes care of activities related to (for example) upgrading software versions and to subscribing computing capacity on-demand from an infrastructure vendor. For the user, this can be viewed as outsourcing the IT management activities related to maintaining an information system. The user leases software instead of buying a license, and simply uses external services. For the vendor, the business means a highly automated software product business with effective network delivery. It also involves operating as a service business, requiring efforts in the management of customer relations.

The benefits of the cloud computing - or SaaS - have been widely discussed from the user point of view. However, the benefits for a cloud provider have received less attention (cf. Armbrust et al., 2010). For the user, SaaS provides online access to software when needed. This reduces costs, since pricing is more flexible than is the case with traditional software licensees (for example allowing pay per use). SaaS also ensures that the latest version of the software is in use; moreover, because a service provider's server runs the software, it frees users from worrying about the technical specification of the computer or the data storage capacity. Thus, cloud computing provides benefits for its users despite some risks, such as unavailability of the service (e.g. because of static in the broadband connection), data confidentiality, data lock-in, etc. (Armbrust et al., 2010). 


\section{Methodology}

This longitudinal case study examines the value network of the firm "Game Cluster" (G-cluster), and the changes in its network over a five-year period. For this study, a total of seven semi-structured open-ended interviews were conducted with five informants. The interviews lasted approximately 45-90 minutes, and each interview was digitally recorded and transcribed verbatim. The first round of interviews was conducted in 2005, and the second in 2010. The interviewees were selected from those persons who had the most in-depth knowledge of the firm's activities, partners, and customers. These informants included the Managing Director, the Vice President, the Chairman of the Board of Directors, the Vice President of Software Engineering, and the Software Engineer. The transcribed interviews were then sent back to the interviewees for comment, and if they found any inaccuracies these were corrected. In addition, telephone and e-mail communication was used to collect further information and to clarify some issues in the data. The website of the firm (including press releases) was also actively followed during the five-year period and used to collect secondary data.

\section{Background of the case firm}

G-cluster, established in 2000, has 25 employees. It provides interactive gaming platforms and games-on-demand services. In the firm's business model, G-cluster licenses game content ( $\mathrm{PC}$ or console games) from the firms that have rights to the games, such as game publishers or game developers. These licensed games are converted to a gaming platform (operated by a network operator) and delivered to the players' set-top boxes or PCs through the Internet. Hence, the processing of the game is dealt with on the server side, and sent to the players (end-users) through video streaming technology. In practice, this means that users can play a game without downloading and installing it onto a device. It also makes it possible to play against other players through the Internet and via in-game communication between players. 


\section{The value network of G-cluster}

The value network of G-cluster in 2005 is shown in Figure 1, and the value of its product offering for the actors in the network is explained below.

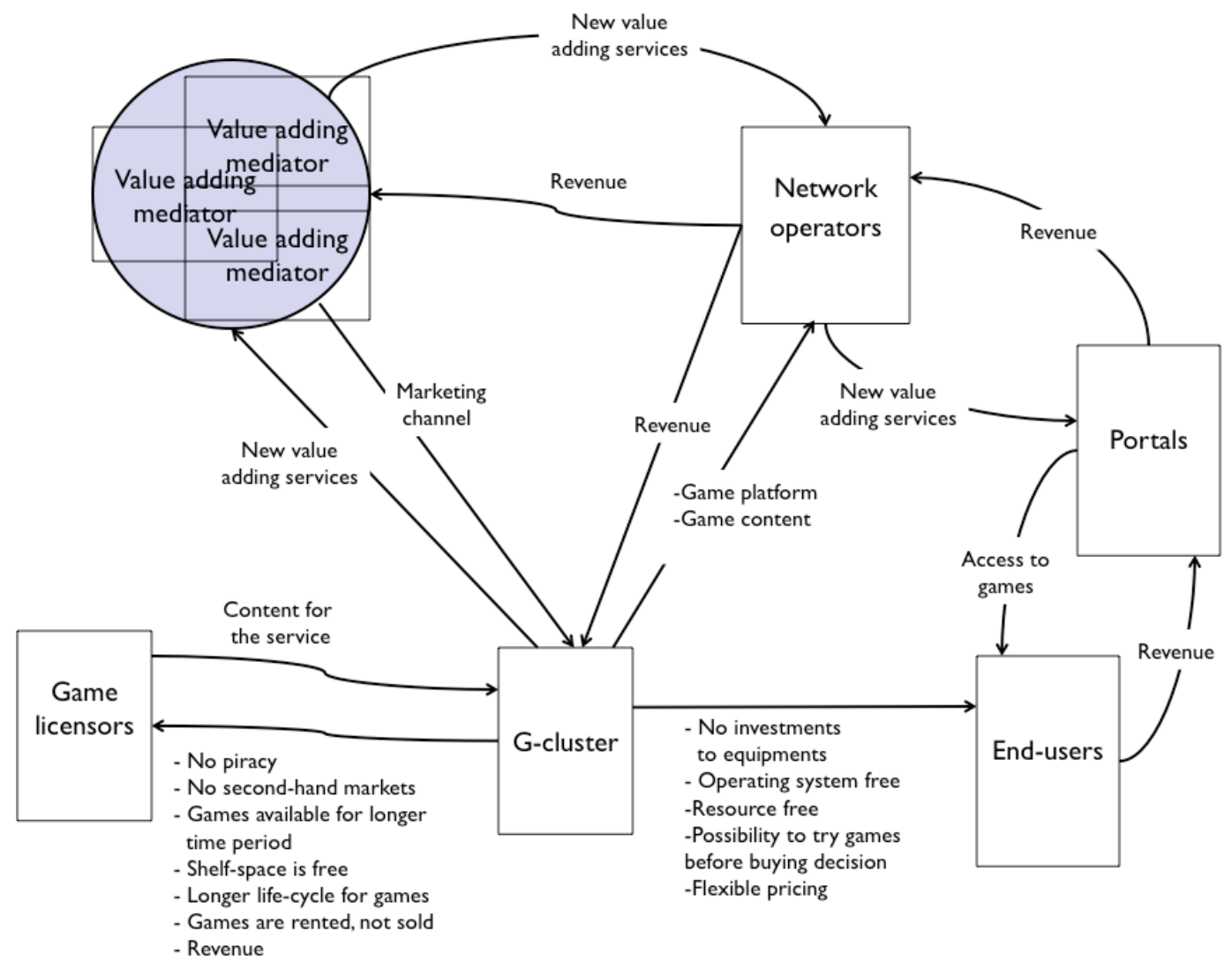

Figure 1. The value network of G-cluster in 2005

\section{Game licensors}

In the value network as it existed in 2005, G-cluster licensed game content from firms that licensed rights to games (e.g. game publishers, game developers). There were several benefits for the game licensors (in addition to revenue) that motivated them to license games to G-cluster's games-on-demand service. Because the game content was streamed to end users, the end-users did not get the game code. This made illegal copying (piracy) impossible. Piracy is a serious 
problem in the games industry, and avoiding illegal copying was a motivating factor for game licensors. One informant explained the matter thus:

"If we look at big markets for games, such as China, it is difficult to sell the same game twice. In many cases, a pirate copy of the game is available there even before a game is officially published."

Delivering the game content virtually also made second-hand markets impossible - another benefit for the game licensors. A major proportion of the annual sales of games comes from second-hand markets. However, game licensors do not benefit from these markets, as their revenue comes only from the sales of new games. In G-cluster's service, older games can be available at a lower price (corresponding to second-hand markets). In addition, in G-cluster's virtual store, shelf space costs nothing. This makes it possible to keep a large number of games available to the end-user for a longer time compared to traditional game stores where the life cycle of a game is relatively short (8-12 weeks) and shelf-space is expensive. Gcluster's games service makes possible a variety of revenue models, and such a range of possibilities is in the interest of game licensors. Unlike the traditional model, where an end-user buys a game from a store, G-cluster's service made it possible to rent the game. Thus, the game could be rented for an hour, a day, or a week, or it could form part of some larger games package.

\section{Value-adding mediators}

In the network, value-adding mediators included three types of firms. These firms were (i) video-on-demand service providers, (ii) set-top box manufacturers, and (iii) middleware software providers. For a small firm such as G-cluster, it was difficult to make contact with the network operators who were their main customers, and who delivered games through their network. Value-adding mediators, who had existing relationships with network operators, helped Gcluster to achieve a contract with the network operators. In addition, video-on- 
demand service providers provided an invoicing system for G-cluster's games-ondemand service. The value of G-cluster's service to the value-adding mediators was the existence of a new feature, one that they were able to add to their existing offering. One informant expressed this as follows:

"There were mutual benefits. We had the same target customers, network operators, the same technical requirements, etc. For us, these firms provided more sales resources, that is, more people who could inform the markets about our products. For them, the benefit was to get more content into their product and in that way, more features to offer to the network operators."

Thus, although there were some license agreements between G-cluster and valueadding mediators, the most important value of the relationships was the mutual benefits that the relationships provided.

\section{Network operators}

G-cluster provided the gaming platform and game content for the network operators, who ran the games on their servers. The network operators had the infrastructure (a pre-existing customer base, computer centers, broadband capacity, etc.) that was needed to deliver G-cluster's games-on-demand service to the end-users. In addition to revenues, G-cluster's service played an important role in extending the network operators' existing product portfolio to the endusers. One informant made the following comment:

"Globally, most of the network operators are in a market situation where they send a letter to customers saying that they have doubled the connection speed of the broadband network, and decreased the price of the connection. So, in this kind of situation it is difficult to increase revenue. However, value-adding services 
such as video-on-demand and our games-on-demand services are one way to increase the offering and the revenue."

\section{Portals}

In 2005, in the G-cluster value network, portals provided access (a website) for the end-users within G-cluster's games-on-demand service. By using a portal's website, end-users were able to log in to the service and select the game that they would like to play. The portals also took care of marketing and billing the customers via the invoicing system that was integrated into their own service. For the portals, G-cluster's service brought revenue without requiring any investment, and it was easily integrated into their current business. One interviewee highlighted this as follows:

"For portals, it was very easy to integrate our service into their own without any additional investments. They only needed to add a link to their website, and the link would give access to our service"

\section{End-users}

End-users using the games provided by G-cluster benefit from the service in several ways. In 2005, the end-users of G-cluster's games-on-demand service were mainly PC users. However, because the actual game was executed on an operator's server, all that was needed from a client computer was the ability to decompress a MPEG stream. This made it possible for end-users to use existing computers without investing in new equipment. The service was also independent of operating systems, and thus it was possible to play the games through various operating systems such as Windows, Macintosh, Linux, etc. In addition, the service freed consumers from worrying about processor power, graphics cards, 
and other technical issues that would be important if they were buying games from a store. One informant explained this as follows:

"Of course it's a huge difference compared to the traditional way, if you think about playing via a PC. You have to have a certain PC, a certain operating system, a certain version of the operating system, certain programs, and it has to have enough memory, resources, etc."

End-users were also able to test the game before deciding to buy, then purchase the game for a certain time. Thus, pricing now became very flexible. End-users could first pay per play, and if they liked the game, they could rent the game for a longer period. Moreover, the game was always ready-to-play because there was no need to download anything.

\section{Changes in the value network}

The value network of G-cluster in 2010 is shown in Figure 2. Over a five-year period, important changes occurred in the market environment and in G-cluster's product, and these impacted on the value network. Firstly, G-cluster changed its target group (end-users) from PC and Internet Protocol Television (IPTV) users (in 2005) to solely IPTV users (in 2010). This change was the consequence of increasing competition in the computer game markets, where simpler games have increasingly become free for the end-user. On the other hand, "heavy" players, those who play more complex games, tend to buy games from a store, and they are willing to invest in game consoles and other equipment. In this situation, Gcluster started to focus solely on the IPTV market, in which it is possible for endusers to play games through a television connected to a broadband network.

Secondly, G-cluster developed its product further, and now offered a ready-made product for the network operators. This meant that the product included components that had previously been provided by value-adding 
mediators or by network portals, such as an invoicing system and a user interface (menu) that enabled users to select the games from its virtual games store. By including these components within the product, the network operators became less dependent on third parties.

Because of these changes, the value previously given by the value-adding mediators (video-on-demand service providers, set-top box manufacturers, middleware software providers) and portals became less valuable, and in fact these mediators were now excluded from the value network. The comprehensiveness of the product range had enabled better access to the network operators, and as a result, no need for many intermediaries. In addition, over a period of five years, G-cluster had come to know the network operators better, and thus it could more readily make direct contact with them. The change in the target customers, from PC users to IPTV users, and the individualized menu, made it possible to remove portals from the value network. As one interviewee commented:

"Although in 2005 we liked to discuss things with all possible actors who were delivering something to the network operators, we've now given up this kind of discussion. Now we discuss directly with the operators. The fact that we have a more comprehensive product has made this possible."

In 2010, G-cluster started to cooperate with a large and well-known server manufacturer. Currently, this cooperation provides mutual benefit "value" to both firms, although there are no business activities (buyer-customer relationship) between G-cluster and the server manufacturer. The relationship is shown with dash lines in Figure 2, since it is not as critical a role as the relationships between G-cluster and the value-adding mediators in the value network of 2005. However, compared to earlier value adding mediators, this cooperation has brought a more reliable and influential partner, one that has helped them to embark on negotiations with new network operators. This has increased G-cluster's 
marketing and sale resources, due to the fact that the sever provider already knew network operators around the world, and was conducting business with them. The cooperation has also helped in getting negotiations under way with the right people on the customer side, with no need to waste time in various meetings before finding the right contact people from the target organization. G-cluster is a very small firm compared to the network operators, so cooperation with a large and well-known server manufacturer has given credibility in business negotiations. Conversely, by including G-cluster's technology within its servers, the server manufacturer gets added value, and this is something it can use when selling its servers to network operators. According to one interviewee:

"Our product is remarkably beneficial to firms that sell servers to network operators. They can say to the network operators that by making a small additional investment, they can get an infrastructure that can be used to deliver our games-on-demand service." 


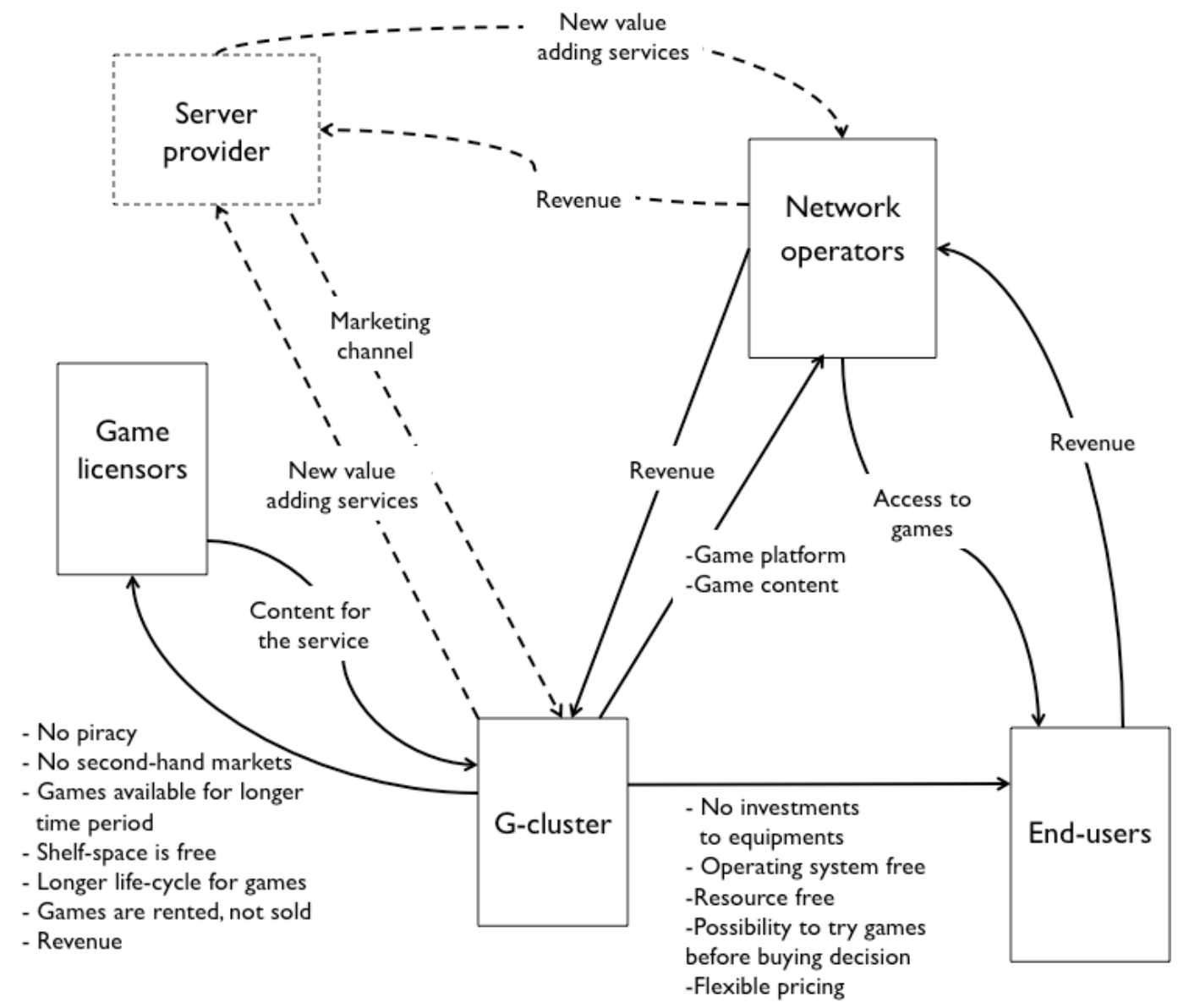

Figure 2. The value network of G-cluster in 2010. 


\section{Discussion and conclusions}

This paper dealt with value-network in cloud computing and the benefits of the network to the actors involved. We highlighted the benefits of cloud computing and SaaS from the provider point of view - an aspect neglected in earlier studies (c.f. Armbrust et al., 2010). The research questions for this study concerned (1) the values of a firm's product for the actors in a network in the cloud computing field, and (2) the ways in which the value network might change over time. In relation to the first question, the case firm was found to provide a rich range of values, such as revenue and added value services. However, there were also intangible benefits such as preventing piracy, having a means to enter a new market segment (corresponding to second-hand markets), and the provision of a new business model (renting). We discovered that all the actors in the value network benefited from G-cluster's product through integration with their existing product or service portfolio.

Our finding - that the cooperation in the value network did not merely

give financial benefits (revenue) but also knowledge and intangible benefits - is in line with the conceptual framework described by Allee (2000), who suggested that value networks create several kinds of benefit for the participating firms. Interestingly, as Figures 1 and 2 show, there is no direct relationship between Gcluster and its end-users, even if they belong to the same value network. We noted that G-cluster's service gave value to end-users, and that end-users were willing to pay for the service. However, the actual revenue came through the network operators. In addition, it appeared that the value in the network benefited not only the customers (end-users) but also other actors in the network. This is in contrast to the view of Anderson et al. (1993), who suggest that the value pertains only to the exchange between the seller and the customer.

As regards the second research question, the case firm involved a new entrant in the industry. The firm entered the market by using partners who provided access to the network operators. Initially, the channel to the end-users was via portals, which provided complementary services (see the value network in 
2005). In this market position the case firm itself acted as an additional market channel for the game licensors. When G-cluster gained a stronger position and was able to provide a full product that satisfied the requirements of the network operator's (see value network, 2010), it was able to simplify the entire value network and to make it more efficient. This demonstrates the dynamic nature of networks (Larson and Starr, 1993; Prashantham and Dhanaraj, 2010) where the importance of the partners in the network may increase or decrease. The changes in G-cluster's value network were based mainly on (i) transformations in the market environment, and (ii) product development. G-cluster had to react to the changes in the computer game market, where increasingly there were free games that decreased their market potential. For this reason they started to focus solely on the IPTV market. G-cluster also developed its product further, in such as way that some actors in the value network became unnecessary (since they no longer provided added value). However, G-cluster was still dependent on the network operators that provided services to end-users. This demonstrates a situation in which a firm is dependent on resources controlled by other firms (see Johanson and Mattsson, 1988). Nevertheless, G-cluster was able to get access to these resources; it acquired a position in the value network such that its product played an important role and gave added value to the network operators' existing product portfolio.

From the managerial point of view, the findings here can be applied to the formation and management of value networks, not just in cloud computing but in general. When a firm enters the market or launches a new product, it is important to assess the potential partners who might benefit from the product, and what these benefits might be - in other words to consider how a firm's product or service might create value for the partner's product portfolio. In this way, the firm can motivate its partners in the network to act in pursuit of a common goal. For example, G-cluster motivated its value-adding mediators to act as a marketing channel toward the network operators; this was done by offering new services that expanded the mediators' product portfolio and made it more attractive for the network operators. However, when a firm develops its product further, there may 
be a need for new partners, and/or earlier partners may become unnecessary. Thus, a firm has to be ready to find new partners and remove unnecessary ones from its network. Managers should also take into account the possibility of important indirect relationships in the value network. For example the relationship between G-cluster and the end-users demonstrates an indirect relationship in which the value does not come directly, but through the partners in the network. However, this indirect connection was also one of the most important, as the entire revenue stream comes from the end-users.

Managers can also make use of cloud services as a means to address market segments that would have not been profitable if traditional means were used. The effective delivery of services via the Internet reduces the marginal costs

of serving yet another customer, and makes it possible to target large numbers of customers who are willing to pay a small price for the services, especially in consumer markets. However, in business-to-business markets, careful analysis is needed, as marketing and sales costs may easily exceed the revenue for the first year (Tyrväinen and Selin, 2011). All this implies that cloud services will be best suited to large consumer markets and to similar professional markets.

\section{References}

Allee, V. (2000), "Reconfiguring the value network," Journal of Business Strategy, Vol. 21 No. 4, pp. 36-39.

Allee, V. (2008), "Value network analysis and value conversion of tangible and intangible assets," Journal of Intellectual Capital, Vol. 9 No. 1, pp. 5-24.

Anderson, J.C., Jain, D.C. and Chintagunta, P.K. (1993), "Customer Value Assessment in Business Markets: A State-of-Practice Study," Journal of Business-to-Business Marketing, Vol. 1 No. 1, pp. 3-29.

Armbrust et al. (2010), "A view of cloud computing," Communication of the $A C M$, Vol. 53 No. 4, pp. 50-58. 
Baxter, R. and Matear, S. (2004), "Measuring intangible value in business-tobusiness buyer-seller relationships: An intellectual capital perspective," Industrial Marketing Management, Vol. 33 No. 6, pp. 491-500.

Griffith, D.A. and Harvey, M.G. (2004), "The influence of individual and firm level social capital of marketing managers in a firm's global network," Journal of World Business, Vol. 39 No. 3, pp. 244-254.

Johanson, J. and Mattsson, L-G. (1988), Internationalisation in Industrial Systems - A Network Approach. In Hood, N. and Vahlne, J-E. (Eds.), Strategies in Global Competition, Croom Helm, London, pp. 287-314.

Johanson, J. and Vahlne, J-E. (2003), "Business Relationship Learning and Commitment in the Internationalization process," Journal of International Entrepreneurship, Vol. 1 No. 1, pp. 83-101.

Kothandaraman, P. and Wilson, D.T. (2001), "The Future of Competition: ValueCreating Networks," Industrial Marketing Management, Vol. 30 No. 4, pp. 379-389.

Larson, A. and Starr, J.A. (1993), "A Network Model of Organization Formation," Entrepreneurship Theory and Practice, Vol. 17 No. 2, pp. 5-15.

Prashantham, S., and C. Dhanaraj (2010), 'The Dynamic Influence of Social Capital on the International Growth of New Ventures," Journal of Management Studies, Vol. 47 No. 6, pp. 967-994.

SIIA (2011), "All about the cloud," Software \& Information Industry Association, available at: www.siia.net/aatc/2011 (accessed 6 April 2011).

Telecom-IT (2011), "Cloud computing - the technology of the future," TelecomIT, available at: www.siia.net/aatc/2011 (accessed 6 April 2011).

Tyrväinen, P. and Selin, J. (2011), "How to Sell SaaS: A Model for Main Factors of Marketing and Selling Software-as-a-Service," Proceedings of the $2^{\text {nd }}$ International Conference on Software Business, Brussels, Belgium.

Westerlund, M. \& Svahn, S. (2008), "A relationship value perspective of social capital in networks of software SMEs," Industrial Marketing Management, Vol. 37 No. 5, pp. 492-501. 